\title{
Application of SIMULINK to Analyze the Unbalanced Operation Characteristics of a Three- Phase Transformer with Non-Identical Winding Impedances
}

\author{
W. C. Yang \\ Department of Electrical Engineering \\ Taipei Chengshih University of Science and Technology
} R.O.C

\author{
W. T. Huang \\ Department of Industrial Education and Technology \\ National Chunghua University of Education \\ R.O.C
}

\author{
W. L. Kao \\ Department of Electrical Engineering \\ Taipei Chengshih University of Science and Technology \\ R.O.C
}

\begin{abstract}
The aim of this paper is to introduce the application of SIMULINK to analyze the unbalanced operation characteristics of a three-phase transformer with non-identical winding impedances. SIMULINK is popular professional simulation software in power industry and departments of electrical and electronic engineering of colleges. If the winding impedances of a three-phase transformer are not identical, unbalanced problems will be produced in power systems. In this paper, the simulation technique for a three-phase transformer with non-identical winding impedances is presented. The unbalanced operation characteristics of a three-phase transformer with non-identical winding impedances are also presented and discussed here.
\end{abstract}

Keywords-SIMULINK; unbalanced characteristic; transformer; winding impedance

\section{INTRODUCTION}

Three-phase transformers are electric devices. Their main tasks are to reduce the high voltage on primary side to a low voltage and to supply balanced three-phase electric power to customers [1]. At present, three-phase transformers are widely applied in power systems of utilities and industry plants. They affect the power supply quality and stability largely.

In order to reduce manufacturing costs, three-phase transformers are usually manufactured by three single-phase transformers [2]. Theoretically, the winding impedances of the three single-phase transformers are identical. In fact, the three winding impedances may not identical due to various factors. If a power system adopts a three-phase transformer with nonidentical winding impedances to supply three-phase electric power, unbalanced operation problems will be produced. Hence, how to get the unbalanced operation characteristics of a three-phase transformer with non-identical winding impedances is an important task for power engineers.
SIMULINK is professional software for simulating power systems or power devices [3]. It is popular with power industry and departments of electrical and electronic engineering of colleges. In this paper, the simulation technique for a three-phase transformer with non-identical winding impedances is presented. The unbalanced operation characteristics of a three-phase transformer with non-identical winding impedances are also presented and discussed here.

\section{EQUIVALENT CIRCUIT}

A three-phase transformer consists of three single-phase transformers. The windings on high-voltage and low-voltage sides of the three single-phase transformers can be connected with delta or wye connection, respectively. A three-phase transformer with delta-wye connection is shown in Figure 1. Generally, the delta connection is the primary side which is connected to a high voltage source. The wye connection is the secondary side which produces low voltage for customers. Delta-wye transformers are widely adopted in power stations of utilities and industry plants. Hence, they are adopted by this paper to present the unbalanced operation characteristics of a three-phase transformer.

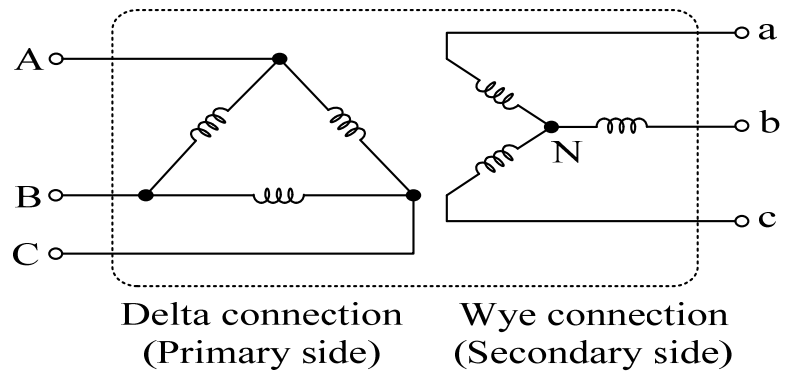

FIGURE I. A THREE-PHASE TRANSFORMER WITH DELTA-WYE CONNECTION. 
For simulating the unbalanced operation characteristics of a delta-wye three-phase transformer, its equivalent circuit has been developed by the coupling-free technique [4]. The equivalent circuit of a delta-wye three-phase transformer is presented in Figure 2. The symbols $\mathrm{y}_{\mathrm{a}}, \mathrm{y}_{\mathrm{b}}$ and $\mathrm{y}_{\mathrm{c}}$ represent the leakage impedances of phase $\mathrm{A}, \mathrm{B}$ and $\mathrm{C}$ windings of the delta-wye three-phase transformer, respectively. The units of the three leakage impedances are all per unit (pu).

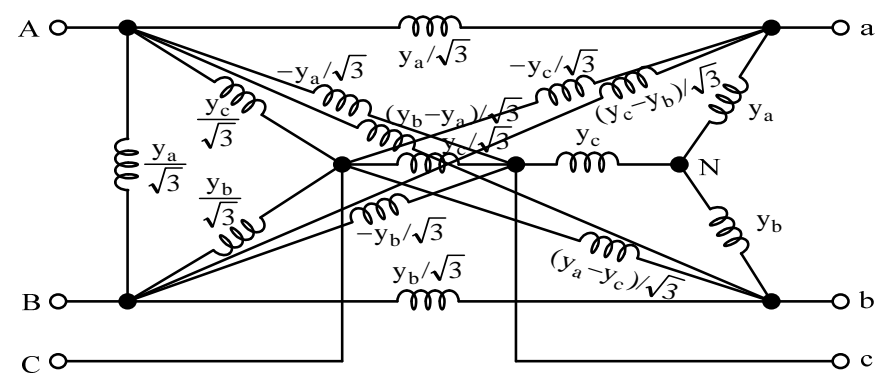

FIGURE II. THE EQUIVALENT CIRCUIT OF A DELTA-WYE THREEPHASE TRANSFORMER.

\section{SIMULATION TECHNIQUE}

SIMULINK is professional software for simulating power systems or devices. It has a powerful simulation module, SimPowerSystems. The SimPowerSystems provides various electric power elements for simulation. Users can select necessary electric power elements to build the equivalent circuit of a power system or device, and then to simulate their operation characteristics. For example, the "Elements" library of the SimPowerSystems provides the basic elements such as breakers, ground, transformers, conductors and loads. In this research, the resistors and reactors in SimPowerSystems were used to build the equivalent circuit of the delta-wye threephase transformer according to the Figure 2. Figure 3 shows the equivalent circuit of the delta-wye three-phase transformer for simulation in SIMULINK.

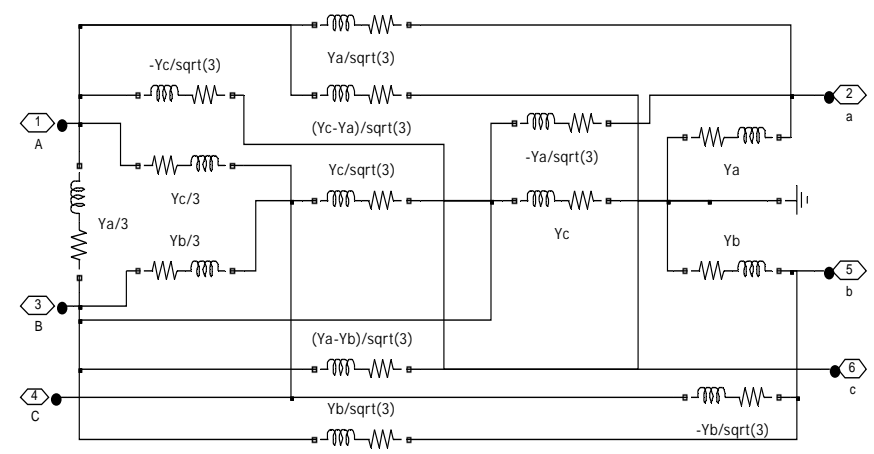

FIGURE III. THE EQUIVALENT CIRCUIT OF THE DELTA-WYE THREE-PHASE TRANSFORMER FOR SIMULATION IN SIMULINK.

\section{TEST SYSTEM}

A test system is proposed in this paper for simulating the unbalanced operation characteristics of a delta-wye threephase transformer. Figure 4 shows the structure of the proposed test system. The test system includes a balanced three-phase voltage source, primary feeders, a delta-wye threephase transformer, secondary feeders, and a three-phase RL load. The balanced three-phase voltage source is modified from the element "Three-Phase Source" which can be gotten from the "electrical sources" library of the SimPowerSystems. The primary and secondary feeders are modified from the elements "Three-phase series RLC Branch" which can be gotten from the "Element" library of the SimPowerSystems. The three-phase RL load is modified from the elements "Three-phase series RLC Load" which also can be gotten from the "Element" library of the SimPowerSystems.

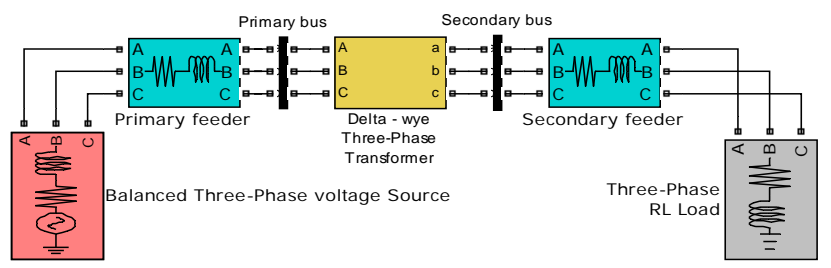

\section{FIGURE IV. THE STRUCTURE OF THE PROPOSED TEST SYSTEM.}

The balanced three-phase voltage source is an ideal power source. Its magnitude is set as $11400 \mathrm{~V}$ line to line. The primary and secondary feeders include three conductors, respectively. Their lengths and impedances are all $100 \mathrm{~m}$ and $0.131+\mathrm{j} 0.371 \Omega / \mathrm{km}$, respectively. The three-phase RL load consumes 50kvar with 0.8 lagging power factor. The rated capacity of the delta-wye three-phase transformer is $100 \mathrm{kVA}$. The rated voltages on primary and secondary side are $11400 \mathrm{~V}$ and $220 \mathrm{~V}$ line to line, respectively. In order to get the information about bus voltages, line currents and power flows, some measuring elements are set in the test system. For making the structure of the test system clear, the adopted measuring elements are all hidden inside the primary and secondary buses.

\section{SIMULATION RESULTS}

The proposed test system has been built in SIMULINK. Several simulation cases for simulating unbalanced operation characteristics of a three-phase transformer also have been carried out. In the simulation work, the impedances of phase B and $\mathrm{C}$ of the delta-wye three-phase transformer were assumed to be equal. The impedance of phase A of the delta-wye threephase transformer was changed at each simulation case. The impedance ratio (IR) is defined in eqn (1) and the change range was from $50 \%$ to $150 \%$. In eqn (1), the basic impedance is the original winding impedance of the three-phase transformer. If the IR is $100 \%$, it means the three winding impedances of the delta-wye three-phase transformer are exactly equal to each other. Besides, the simulation duration for all simulation cases was 0.5 s. Simulation results including voltages, currents and unbalance ratios on the primary and secondary sides of the delta-wye three-phase transformer are presented and discussed as follows. The voltage and current unbalanced ratios (VUR and IUR) are defined in eqn (2) and (3), respectively. In eqn (2), the voltages $V_{A}, V_{B}$ and $V_{C}$ are the phase voltages of three-phase transformer. The $V_{\text {avg }}$ is the average of the voltages $V_{A}, V_{B}$ and $V_{C}$. In eqn (3), the currents $I_{A}, I_{B}$ and $I_{C}$ are the line currents of three-phase transformer. The $\mathrm{I}_{\mathrm{avg}}$ is the average of the currents $\mathrm{I}_{\mathrm{A}}, \mathrm{I}_{\mathrm{B}}$ and $\mathrm{I}_{\mathrm{C}}$.

$$
\text { IR }=\frac{\text { winding impedance }}{\text { basic impedance }} \times 100 \%
$$




$$
\begin{gathered}
\text { VUR }=\frac{\operatorname{Max}\left[\| \mathrm{V}_{\text {avg }}|-| \mathrm{V}_{\mathrm{A}}||,|| \mathrm{V}_{\text {avg }}|-| \mathrm{V}_{\mathrm{B}}||,|| \mathrm{V}_{\text {avg }}|-| \mathrm{V}_{\mathrm{C}} \mid,\right]}{\left|\mathrm{V}_{\text {avg }}\right|} \times 100 \% \\
\operatorname{IUR}=\frac{\operatorname{Max}\left[\left|\mathrm{I}_{\text {avg }}\right|-\left|\mathrm{I}_{\mathrm{A}}\right|,||\left|\mathrm{I}_{\text {avg }}\right|-\left|\mathrm{I}_{\mathrm{B}}\right|,|,| \mathrm{I}_{\text {avg }}|-| \mathrm{I}_{\mathrm{C}} \mid,\right]}{\left|\mathrm{I}_{\text {avg }}\right|} \times 100 \%
\end{gathered}
$$

Figures 5 and 6 show the voltage and current waveforms on the secondary side of the delta-wye three-phase transformer, respectively. The simulation results illustrate that the threephase voltages and currents are unbalanced when the winding impedance of phase $\mathrm{A}$ is not equal to phases $\mathrm{B}$ and $\mathrm{C}$.

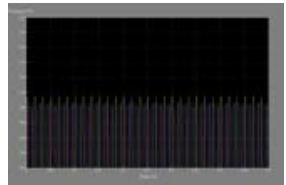

(a) IR=50\%

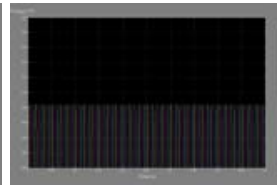

(b) IR $=100 \%$

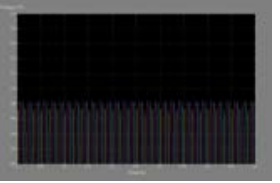

(c) IR $=150 \%$

FIGURES V. VOLTAGE WAVEFORMS ON THE SECONDARY SIDE OF THE DELTA-WYE THREE-PHASE TRANSFORMER.

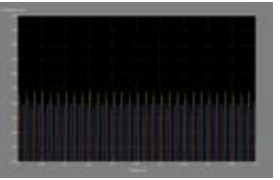

(a) $\mathrm{IR}=50 \%$ (b) $\mathrm{IR}=100 \%$

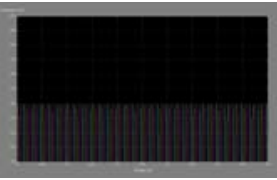

I. CURRENT WAVEFORMS ON THE SECONDARY

Figures 7 and 8 show the VURs and IURs on the primary and secondary sides of the delta-wye three-phase transformer, respectively. The simulation results illustrate that the winding impedances of a three-phase transformer are more different, the unbalance degrees of voltages and currents are larger.

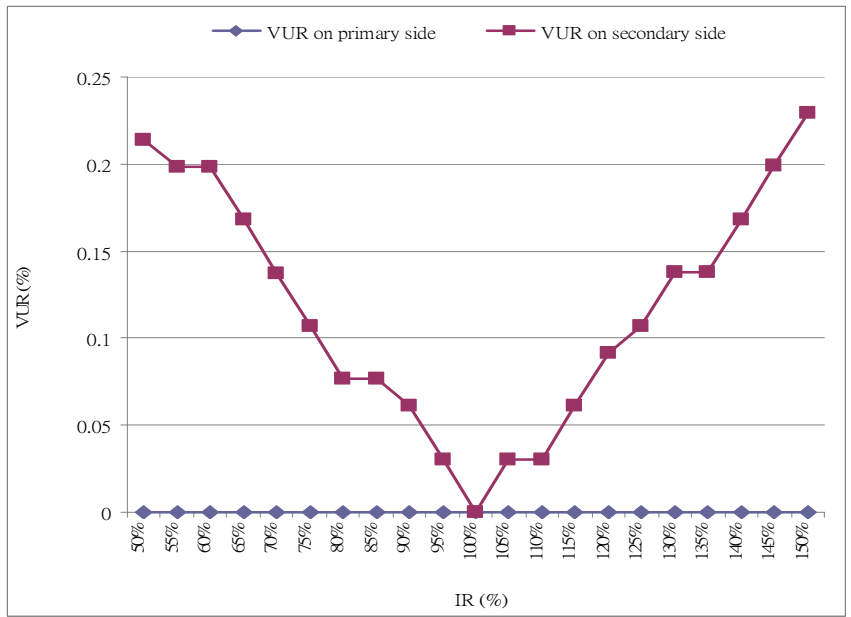

FIGURES VII. VURS ON THE PRIMARY AND SECONDARY SIDES OF THE DELTA-WYE THREE-PHASE TRANSFORMER.

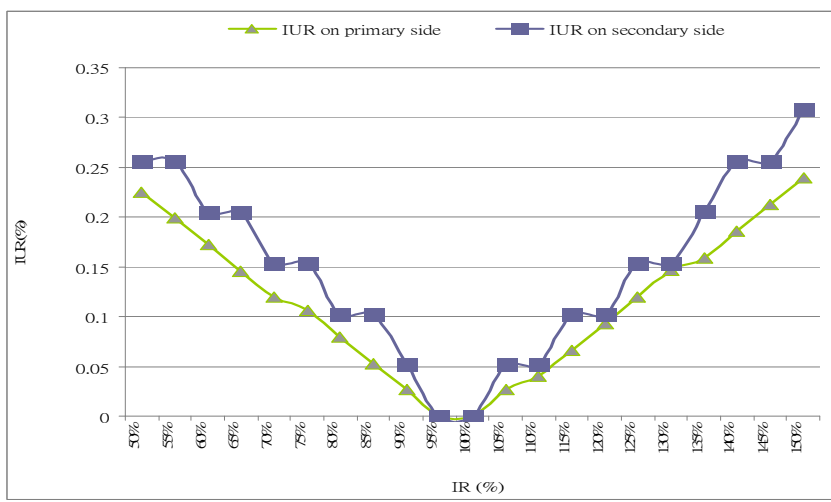

FIGURES VIII. IURS ON THE PRIMARY AND SECONDARY SIDES OF THE DELTA-WYE THREE-PHASE TRANSFORMER.

\section{CONCLUSIONS}

The simulation technique for a three-phase transformer with non-identical winding impedances has been presented in this paper. The unbalanced operation characteristics of a threephase transformer with non-identical winding impedances have been also presented and discussed. The simulation results illustrate that if the winding impedances are not exactly equal to each other, the operation characteristics including voltages and currents will be unbalanced.

Voltage and current unbalances are harmful to electric power devices [5, 6]. The unbalance is larger; the injury to electric power devices is larger, too. Hence, power engineers should take special care whether the winding impedances of three-phase transformers are exactly equal to each other.

\section{ACKNOWLEDGMENT}

The authors would like to thank the Ministry of Science and Technology of the Republic of China, Taiwan, for financially supporting this research under Contract No. MOST 103-2221-E-149 -007.

\section{REFERENCES}

[1] Kersting, W. H., Distribution System Modeling and Analysis, Taylor \& Francis: London, p. 241-292, 2013.

[2] Chen, T.H. Yang, W.C. Guo, T.Y. \& Pu, G.C., Modeling and analysis of asymmetrical three-phase distribution transformer banks with mid-tap connected to the secondary neutral conductor. International Journal of Electrical Power Systems Research, 54(2), pp. 83-89, 2000.

[3] Mohan, N., Advanced Electric Drives: Analysis, Control, and Modeling Using MATLAB / Simulink, John Wiley \& Sons: New Jersey, p. 3-6, 2014.

[4] Smolleck, H.A. \& Shoults, R.R., A classroom method for structuring the bus admittance matrix from synthesis of coupling-free equivalents. IEEE Transactions on Power Systems, 7(1), pp. 383 - 388, 1992.

[5] Xu, Y. Tolbert, L.M. Kueck, J.D. \& Rizy, D.T., Voltage and current unbalance compensation using a static var compensator. IET Power Electronics, 3(6), pp. 977 - 988, 2010.

[6] Chua, K.H. Yun, S.L. Taylor, P. Morris, S. \& Jianhui W., Energy storage system for mitigating voltage unbalance on low-voltage networks with photovoltaic systems. IEEE Transactions on Power Systems, 27(4), pp. 1783 - 1790, 2012. 